\title{
Nighttime D region electron density measurements from ELF- VLF tweek radio atmospherics recorded at low latitudes
}

\author{
Ajeet K. Maurya, ${ }^{1}$ B. Veenadhari, ${ }^{2}$ Rajesh Singh, ${ }^{1}$ Sushil Kumar, ${ }^{3}$ M. B. Cohen, ${ }^{4}$ \\ R. Selvakumaran, ${ }^{2}$ Sneha Gokani, ${ }^{1}$ P. Pant, ${ }^{5}$ A. K. Singh, ${ }^{6}$ and Umran S. Inan ${ }^{4,7}$ \\ Received 27 April 2012; revised 27 August 2012; accepted 14 September 2012; published 14 November 2012.
}

[1] Dispersive atmospherics (tweeks) observed during 2010 simultaneously at two low-latitude stations, Allahabad (geomagnetic latitude, $16.05^{\circ} \mathrm{N}$ ) and Nainital (geomagnetic latitude, $20.48^{\circ} \mathrm{N}$ ), have been used to estimate the nighttime $\mathrm{D}$ region electron density at the ionospheric reflection height under the local nighttime propagation (21:00-02:00 LT or 15:30-20:30 UT). The analysis of simultaneously recorded tweeks at both the stations on five international quiet days during one month each from summer (June), winter (January), and equinox (March) seasons shows that the D region electron density varies $21.5-24.5 \mathrm{~cm}^{-3}$ over the ionospheric reflection height of $85-95 \mathrm{~km}$. The average values of Wait lower ionospheric parameters: ionospheric reference height $h^{\prime}$ and sharpness factor $\beta$ are almost same during winter $\left(85.9-86.1 \mathrm{~km}, 0.51-0.52 \mathrm{~km}^{-1}\right)$ and equinox (85.6-85.7 km, $0.54 \mathrm{~km}^{-1}$ ) seasons. The values of $h^{\prime}$ and $\beta$ during summer season are about $83.5 \mathrm{~km}$ and $0.60 \mathrm{~km}^{-1}$ at both stations. Overall, equivalent electron density profile obtained using tweek method shows lower values of electron density by about $5-60 \%$ than those obtained using the International Reference Ionosphere (IRI-2007) model and lower/higher by $2-68 \%$ than those obtained using rocket technique. The electron density estimated using all three techniques (tweek, IRI-2007, and rocket) is consistent in the altitude range of $82-98 \mathrm{~km}$. The estimated geographic locations of causative lightnings of tweeks were matched with the locations and times of lightnings detected by the World-Wide Lightning Location Network (WWLLN). The WWLLN detected about $27.5 \%$ of causative lightnings of tweeks simultaneously observed at both the stations.

Citation: Maurya, A. K., B. Veenadhari, R. Singh, S. Kumar, M. B. Cohen, R. Selvakumaran, S. Gokani, P. Pant, A. K. Singh, and U. S. Inan (2012), Nighttime D region electron density measurements from ELF-VLF tweek radio atmospherics recorded at low latitudes, J. Geophys. Res., 117, A11308, doi:10.1029/2012JA017876.

\section{Introduction}

[2] The $\mathrm{D}$ region of ionosphere ranges from $\sim 60-75 \mathrm{~km}$ in the day and $\sim 75-95 \mathrm{~km}$ in the night [Hargreaves, 1992]. It is the lowest part of Earth's ionosphere where collisions between charged particles and neutrals dominate. It plays an important role in the propagation of extremely low frequency (ELF: 30-3000Hz) and very low frequency (VLF: 3-30 kHz)

\footnotetext{
${ }^{1}$ KSK Geomagnetic Research Laboratory, IIG, Allahabad, India.

${ }^{2}$ Indian Institute of Geomagnetism, New Panvel, India.

${ }^{3}$ School of Engineering and Physics, University of the South Pacific, Suva, Fiji.

${ }^{4}$ Department of Electrical Engineering, Stanford University, Stanford, California, USA.

${ }^{5}$ Aryabhatta Research Institute of Observational Sciences, Nainital, India.

${ }^{6}$ Physics Department, Banaras Hindu University, Varanasi, India. Turkey.

${ }^{7}$ Department of Electrical Engineering, Koc University, Istanbul,

Corresponding author: R. Singh, KSK Geomagnetic Research Laboratory, IIG, Chamanganj, Allahabad, Uttar Pradesh 221505, India. (rajeshsing03@gmail.com)

(C)2012. American Geophysical Union. All Rights Reserved. 0148-0227/12/2012JA017876
}

waves through the Earth-ionosphere waveguide (EIWG) bounded below by the ground or the ocean and above by the $\mathrm{D}$ region of the ionosphere. The $\mathrm{D}$ region is too high for balloons and too low for the satellite measurements. The electron recombination and attachment rates in this region are so high that the free electron density is very small $\left(<10^{3} \mathrm{~cm}^{-3}\right)$ especially in the nighttime. Ground based radio sounding of the $\mathrm{D}$ region particularly at the night by ionosonde, incoherent scatter and partial reflection radars do not work because of its low electron density [Hargreaves, 1992]. MF radars have been used [Igarashi et al., 2000] at some locations, but high cost of their operation is the main hindrance. For in situ measurements of the lower-ionosphere (up to $\sim 150 \mathrm{~km}$ ) rocket flights have been utilized [Maeda, 1971; Subbaraya et al., 1983; Gupta, 1998; Nagano and Okada, 2000; Friedrich and Torkar, 2001]. Rocket measurements of the D region widely utilize either of two techniques; Faraday rotation [e.g., Friedrich and Torkar, 2001] and Langmuir probe [e.g., Subbaraya et al., 1983]. Friedrich and Torkar [2001] have given a historical review of the $\mathrm{D}$ region rocket measurements globally. They have used about 118 rocket profiles to establish a model for nonauroral ionosphere. Their observations dealt with the rocket flights 
which were evenly distributed over the whole year, seasons, solar activity, day/night conditions covering up to $60^{\circ}$ geomagnetic latitude. But limitation with the rocket technique is that it can be used only episodically and has limited spatial coverage, and cannot be used for continuous monitoring of the $\mathrm{D}$ region. Thus the $\mathrm{D}$ region remains the least studied region of ionosphere. Since VLF waves are reflected by the D region, fixed frequency VLF transmitter signals also have been successfully used to study the morphological features of the D region [Thomson, 1993; Bainbridge and Inan, 2003; Thomson et al., 2007; Thomson and McRae, 2009]. The disadvantage with VLF transmitter technique is its limited spatial coverage along the propagation path due to fixed number of VLF transmitters.

[3] The ELF-VLF signals radiated by lightning discharges (global lightning flash rate $\sim 50-100 \mathrm{~s}^{-1} \mathrm{~km}^{-2}$ ) [Rakov and Uman, 2006] can be used to investigate the D region ionosphere globally. It is well known that lightning strikes radiate powerful radio bursts over a wide frequency range from few $\mathrm{Hz}$ to several MHz [Weidman and Krider, 1986] with a maximum spectral energy near $10 \mathrm{kHz}$ [Uman, 1987; Ramachandran et al., 2007]. The radio bursts from the lightnings are called atmospherics or "sferics" in short which propagate in the EIWG with low attenuation rate (2-3 dB $1000 \mathrm{~km}^{-1}$ ) [Yamashita, 1978; Davies, 1990]. The D region has been studied using the VLF sferics [Cummer et al., 1998] and ELF sferics [Cummer and Inan, 2000] modeling using the long-wave propagation capability (LWPC) code developed by U.S. Navy. They simulated for a variety of ionospheres, the VLF and ELF spectra of sferics received at 1000-2000 km away from the lightning sources. Using the same technique, Cheng et al. [2006] obtained the night-tonight variation of the $\mathrm{D}$ region electron density over the East coast of the United States and compared it with the past nighttime rocket based data obtained at similar latitudes.

[4] We have utilized the cutoff frequencies of different modes of dispersed sferics known as 'tweeks' to estimate the nighttime D region electron density and Wait ionospheric parameters. Earlier studies on tweeks were mainly focused on the propagation properties of tweeks [Outsu, 1960; Yano et al., 1989a, 1989b; Yedemsky et al., 1992; Hayakawa et al., 1994, 1995; Sukhorukov and Stubbe, 1997; Ferencz, 2004; Ferencz et al., 2007; Kumar et al., 2008]. But in recent years the main focus has been to investigate the $\mathrm{D}$ region ionosphere. Ohya et al. [2003] estimated equivalent nighttime electron density at the tweek reflection height at the low and middle latitudes by accurately reading the cutoff frequency of tweeks. They estimated equivalent electron density in the range of $20-28 \mathrm{~cm}^{-3}$ at the ionospheric reflection height of $80-85 \mathrm{~km}$. Tweeks have also been used to estimate the ionospheric reflection height and their propagation distances along the propagation path [Kumar et al., 1994, 2008, 2009; Hayakawa et al., 1994; Maurya et al., 2010, 2012; Singh et al., 2011]. Kumar et al. [2009] developed a simple technique to calculate Wait ionospheric parameters; ionospheric reference height $h^{\prime}$ and exponential sharpness factor $\beta$ from the cutoff frequencies of multimode tweeks observed at Suva, Fiji. The $h^{\prime}$ represents virtual reflection height in $\mathrm{km}$ and $\beta$ represents the gradient in the $\mathrm{D}$ region electron density in $\mathrm{km}^{-1}$.

[5] In the present work we have utilized simultaneously recorded tweeks at the Indian low-latitude stations, Allahabad and Nainital, during one year period January to December 2010 , on five international quiet days during one month from summer (June), winter (January) and equinox (March) seasons, to study seasonal and day-to-day variability of the nighttime $\mathrm{D}$ region reflection height and the electron density at the reflection height. We also present first results on nocturnal seasonal variation of $h^{\prime}$ and $\beta$ using tweeks observed at these stations. The values of $h^{\prime}$ and $\beta$ were obtained using tweek method developed by Kumar et al. [2009]. The previous studies on $h^{\prime}$ and $\beta$ estimated using ELF-VLF sferics [Cummer et al., 1998; Cummer and Inan, 2000; Cheng et al., 2006; Han and Cummer, 2010a, 2010b; Han et al., 2011] utilized data from few days to few months. In the present study we mainly focus on seasonal variation of $h^{\prime}$ and $\beta$. The average values of $h^{\prime}$ and $\beta$ have been used to obtain the electron density profile of the nighttime $\mathrm{D}$ region up to 100 $\mathrm{km}$ altitude during three seasons (summer, winter and equinox). Direction finding technique has been utilized to locate the source positions of tweeks (causative lightning discharges) to determine the path of propagation and hence the geographical area under investigation.

\section{Summary of the Formulas Utilized}

[6] The EIWG is taken with perfectly reflecting walls separated by a distance $h$. The electromagnetic field in the waveguide can be composed of a sequence of independent field structures (modes) that propagate with different group velocities. Each mode is defined by its cutoff frequency $\left(f_{c m}\right)$. The $f_{c m}$ of $m$ th mode is given [Budden, 1961] as

$$
f_{c m}=\frac{m c}{2 h}
$$

where $c$ is velocity of light in free space and $h$ is the tweek reflection height.

[7] The electron density $n_{e}$ at the $h$ is estimated using the expression obtained by Shvets and Hayakawa [1998] and also utilized by Ohya et al. [2003] given as

$$
n_{e}=1.39 \times 10^{-2} f_{\mathrm{cm}}\left[\mathrm{cm}^{-3}\right] .
$$

The group velocity $V_{g m}$ in the homogeneous spherical EIWG of $m$ th mode is given [Ohya et al., 2008; Yano et al., 1989a] as

$$
V_{g m}=c\left[\left(1-\left(f_{c m} / f\right)^{2}\right)\right]^{1 / 2} /\left(1-c / 2 R f_{c m}\right)
$$

where $R$ is the radius of the Earth.

[8] By calculating difference in arrival times, $\delta t=t_{1}-t_{2}$ between two frequencies $f_{1}$ and $f_{2}$ close to $f_{c m}$ of tweeks, the $V_{g m}$ and hence the distance $d$ propagated by tweeks in the spherical EIWG can be calculated using

$$
d=\delta t\left(\frac{V g f_{1} \times V g f_{2}}{V g f_{1}-V g f_{2}}\right)
$$

where $V_{g f 1}$ and $V_{g f 2}$ are the group velocities of waves centered at the frequencies $f_{1}$ and $f_{2}$, respectively.

[9] The distribution of charged particles in the ionosphere depends in a complicated way on latitude, solar zenith angle, season, and solar activity etc. In the simplest approach, the exponential increase of the lower ionospheric electron 
density $n_{e}$ expressed in $\mathrm{cm}^{-3}$, described by Wait profile valid up to about $100 \mathrm{~km}$ altitude [Wait and Spies, 1964] is obtained as

$$
n_{e}(h)=1.43 \times 10^{7} \exp \left(-0.15 h^{\prime}\right) \exp \left[(\beta-0.15)\left(h-h^{\prime}\right)\right] .
$$

\section{Data and Analysis}

[10] The ELF-VLF data recording system at both the sites, Allahabad and Nainital, consists of Stanford University designed Atmospheric Weather Electromagnetic System for Observation, Modeling and Education (AWESOME) VLF receiver [Cohen et al., 2010]. Observational sites were established as a part of global AWESOME network under the auspices of the International Heliophysical Year [Scherrer et al., 2008; Singh et al., 2010]. AWESOME system can record both broadband and narrow band data. Broadband data was recorded in the synoptic mode with 1 min at every 15 min interval. Narrowband data recording made in continuous mode gives the amplitude and phase of VLF transmitter signals which is not a part of present study. Broadband data is analyzed using a Matlab code which produces dynamic spectrogram of selected durations showing atmospherics, tweeks and whistlers. The first-order cutoff frequency $f_{c}$ of tweeks in spectrograms was measured and used to calculate the ionospheric reflection height $h$ and the $\mathrm{D}$ region electron density $n_{e}$ at the reflection height. The arrival times $\left(t_{1}\right.$ and $\left.t_{2}\right)$ of frequencies $\left(f_{1}\right.$ and $\left.f_{2}\right)$ were measured to determine propagation distance $d$ of the tweeks. These frequencies and corresponding arrival times of tweek frequency components were measured with frequency and time resolutions of $25.8 \mathrm{~Hz}$ and $1 \mathrm{~ms}$, respectively, which correspond to an error of $\sim 1.5 \mathrm{~km}$ in the reflection height for first mode and which reduces with the increase in the modes, $\sim 0.40 \mathrm{~cm}^{-3}$ in the electron density and $\sim 500 \mathrm{~km}$ in the propagation distance. The error in electron density and propagation distance is same for all modes. We have utilized simultaneously recorded tweeks at Allahabad (geographic latitude, $25.40^{\circ} \mathrm{N}$; geographic longitude, $81.93^{\circ} \mathrm{E}$; geomagnetic latitude, $16.05^{\circ} \mathrm{N}$ ) and Nainital (geographic latitude, $29.35^{\circ} \mathrm{N}$; geographic longitude, $79.45^{\circ} \mathrm{E}$; geomagnetic latitude, $20.48^{\circ} \mathrm{N}$ ) on five international quiet days during one month from summer (June), winter (January) and equinox (March) seasons under the pure nighttime propagation (21:00-02:00 LT or 15:30 UT-20:30 UT). A total of 1008 pair of tweeks (2016 tweeks) simultaneously observed were selected on the basis of clearly visible tweeks with intensity levels $\geq 60 \mathrm{~dB}$ as seen in the spectrograms. Tweeks observed within $2.0 \mathrm{~ms}$ interval at both the stations which corresponds to a distance of $600 \mathrm{~km}$ have been considered as simultaneously occurring tweeks as they were most likely originated from the same lightning source. The above selection criteria provided us with 400 pairs of tweeks during summer, 320 pairs during equinox and 288 pairs during winter. Out of 1008 pairs of tweeks, we have selected 990 pairs of tweeks with propagation distance $\leq 5000 \mathrm{~km}$ to avoid error in the reflection height and electron density due to tweeks coming from dayside propagation paths particularly for those tweeks which come from eastwest directions. Finally, under this selection criterion we were left with 391 pairs during summer, 284 during winter and 315 during equinox.
[11] There are three possible methods of calculating electron density from tweeks: (1) using first-order mode cutoff frequency of tweeks and equations (1) and (2); (2) using the cutoff frequency of clear higher modes $(m \geq 1)$ of tweeks and equations (1) and (2); and (3) using the second method, we first calculate the electron density $n_{e}$ and the reflection height $h$ at least using two modes of same tweek. The substitutions of $h$ and $n_{e}$ in equation (5) yield equations dealing with $h^{\prime}$ and $\beta$ corresponding to each value of $h$ and $n_{e}$ which on solving give values of $h^{\prime}$ and $\beta$ [Kumar et al., 2009]. Here, we have used above three methods and the results have been discussed and compared with rocket data and International Reference Ionosphere (IRI-2007) model.

\section{Results and Discussion}

\subsection{General Overview of Tweek Characteristics at Allahabad and Nainital}

[12] Broadband data recording at both the stations started in the year 2007 in the synoptic mode with $1 \mathrm{~min}$ at every 15 min. Detailed analysis of tweek occurrence at Allahabad and Nainital shows that tweeks occur only in the local night between 18:00 and 06:00 LT [Maurya et al., 2012]. As an example, spectrograms containing typical multimode (up to 5th mode) tweeks observed simultaneously at both the sites on 16 March 2010 at 17:00 UT and on 14 June 2010 at 18:15 UT are shown in Figure 1 (local time $(\mathrm{LT})=\mathrm{UT}+5.5 \mathrm{~h}$ ). The average tweek duration (dispersed section) is in the range of $8-48 \mathrm{~ms}$ at both the stations. The tweek duration of 10-50 ms remains same during winter and equinox seasons whereas during summer the tweek duration is comparatively less $(5-35 \mathrm{~ms})$. Seasonal variation in tweek duration indicates that during summer tweeks arrive from nearby lightning sources. It is due to the monsoon season (June-August) in India during summer when most lightning occur in India, with more lightings occurring around these stations, whereas during equinox and winter most of tweek lightning sources are located far in the Asia Oceanic Region. Kumar et al. [2008] reported the dispersion duration of 15-60 ms of the tweeks observed in the South Pacific Region. Reznikov et al. [1993] found tweek duration in the range of 40-50 ms, which may reach up to $100 \mathrm{~ms}$. Thus tweek duration at our stations is comparatively less as compared with that reported by Reznikov et al. [1993] and Kumar et al. [2008]. It is due to comparatively less propagation distance of tweeks to our stations as a good portion of the propagation path is over the land which offers more attenuation as compared to propagation over the ocean [Prasad, 1981]. Seasonal pattern of tweek occurrence shows a maximum during summer and almost same occurrence during winter and equinox at both the stations [Maurya et al., 2012]. During summer tweeks occur more frequently at Nainital than at Allahabad but during winter and equinox seasons tweek occurrence is more at Allahabad than at Nainital.

\subsection{Nighttime D Region Reflection Height and Electron Density}

[13] The D region of ionosphere acts as a good electrical conductor at the ELF and VLF frequencies. Lightning generated ELF-VLF tweeks form a useful diagnostic tool to estimate the nighttime ionospheric reflection height $h$ and the 

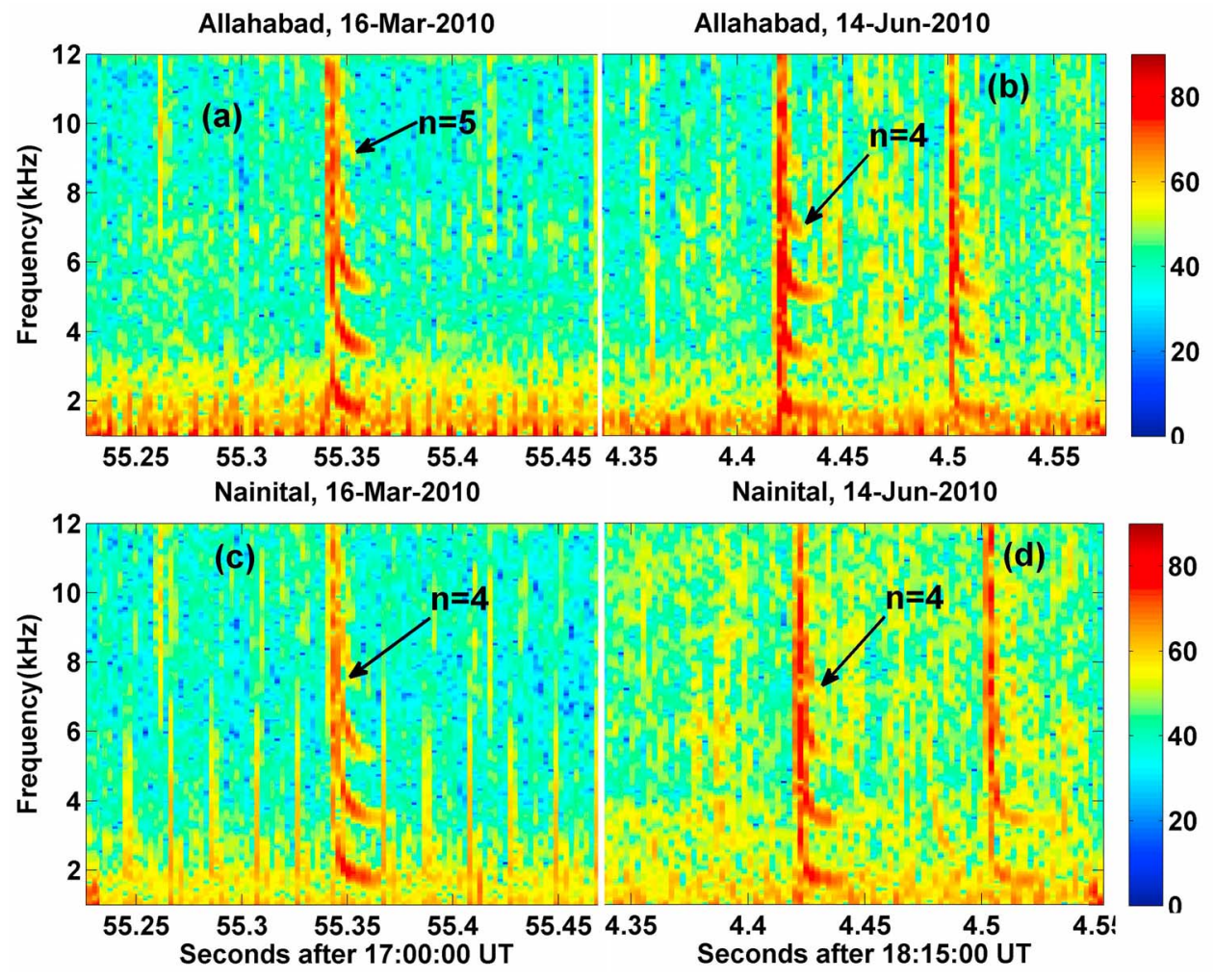

Figure 1. Spectrograms showing typical tweeks observed simultaneously at Allahabad and Nainital.

electron density $n_{e}$ at $h$. The $h$ at Allahabad and Nainital during three seasons (Summer, Winter, Equinox) determined from the cutoff frequency of first mode of tweeks and plotted in Figure 2 shows nearly constant increase in the $h$ with time for all three seasons as indicated by the linear fit lines. The linear fit equations $y(\mathrm{~km})=m x+c$ are shown on the top of Figure 2 where $x$ is in hours. Table 1 shows maximum and minimum values of $h$ observed at both the stations during summer, winter and equinox seasons. The maximum and minimum values of $h$ are lower during equinox and winter as compared to those during summer. The $h$ also shows the dayto-day variability which is up to $9 \mathrm{~km}$ with a maximum variation of about $1-2 \mathrm{~km}$ on any day in any $1 \mathrm{~h}$ duration (not shown here). It is also noted from linear fit equations shown in each panel of Figure 2 that temporal variability in the $h$ during selected period is higher during summer as compared to winter and equinox seasons with almost same variation during winter and equinox at both the stations.

[14] By measuring the first mode cutoff frequency of tweeks and using equation (2) the $n_{e}$ at the $h$ has been calculated. Figure 3 shows variation in the nighttime $n_{e}$ at tweek $h$ during summer, winter and equinox seasons both at Allahabad and Nainital. It is noted that $n_{e}$ is higher by $2 \mathrm{~cm}^{-3}$ during the summer as compared to that during winter and equinox seasons. The temporal variation of $n_{e}$ shows decrease in $n_{e}$ with time during three seasons. Average value of $n_{e}$ at Allahabad on selected days $(15 \mathrm{~d})$ varies $21-24.5 \mathrm{~cm}^{-3}$ at the $h$ of $85-95 \mathrm{~km}$ and at Nainital $21.5-24 \mathrm{~cm}^{-3}$ at the $h$ of $86-95 \mathrm{~km}$. Using the same method, Ohya et al. [2003] estimated $n_{e}$ in the range from 20 to $28 \mathrm{~cm}^{-3}$ at the $h$ of $80-85 \mathrm{~km}$ for a midlatitude Japanese station.
[15] The $h$ and $n_{e}$ variations with time can be understood mainly in terms of electron loss process and recombination in absence of major ionizing sources from sun. However, chemistry, ionization and recombination cycle of the $\mathrm{D}$ region are complicated. The period of observation in present study falls under low solar activity period of solar cycle 24 with tweek propagation paths mainly over the low-latitude and equatorial regions. Taking this into consideration we have tried to explain possible factors of the nighttime $\mathrm{D}$ region variations shown in Figures 2 and 3. Ohya et al. [2011] reported that about $67 \%$ of nighttime lower ionospheric ionization is caused by Lyman $\alpha$ and Lyman $\beta$ coming from the geocorona which ionizes $\mathrm{NO}$ and $\mathrm{O}_{2}$ at $95 \mathrm{~km}$ altitude. They have estimated electron densities at $95 \mathrm{~km}$ for $\mathrm{NO}^{+}$and $\mathrm{O}_{2}^{+}$which is about $5.5 \times 10^{2} \mathrm{~cm}^{-3}$. Electron density at the reflection height estimated from first mode cutoff frequency of tweeks in the present work is less than $5.5 \times 10^{2} \mathrm{~cm}^{-3}$ during three seasons. The less electron density in the nighttime can also be due to change in the neutral temperature in the recombination effect which is about a factor of ten [Ohya et al., 2011]. Another important source of ionization during nighttime is Galactic Cosmic Rays (GCRs) which has nearly half of ionization rate of Lyman $\alpha$ at $85 \mathrm{~km}$ altitude [Thomson et al., 2007]. The GCRs intensity varies with solar activity with maximum during solar minimum [Heaps, 1978]. The ionization by GCRs also depends on the geomagnetic latitude with minimum at the geomagnetic equator [Heaps, 1978]. Since period of study falls under solar minimum, GCRs are supposed to be the important ionizing source at the low and equatorial latitudes and hence an understating of GCRs variability during different seasons at the low and equatorial latitudes is essential to explain the $\mathrm{D}$ region electron density variation. 

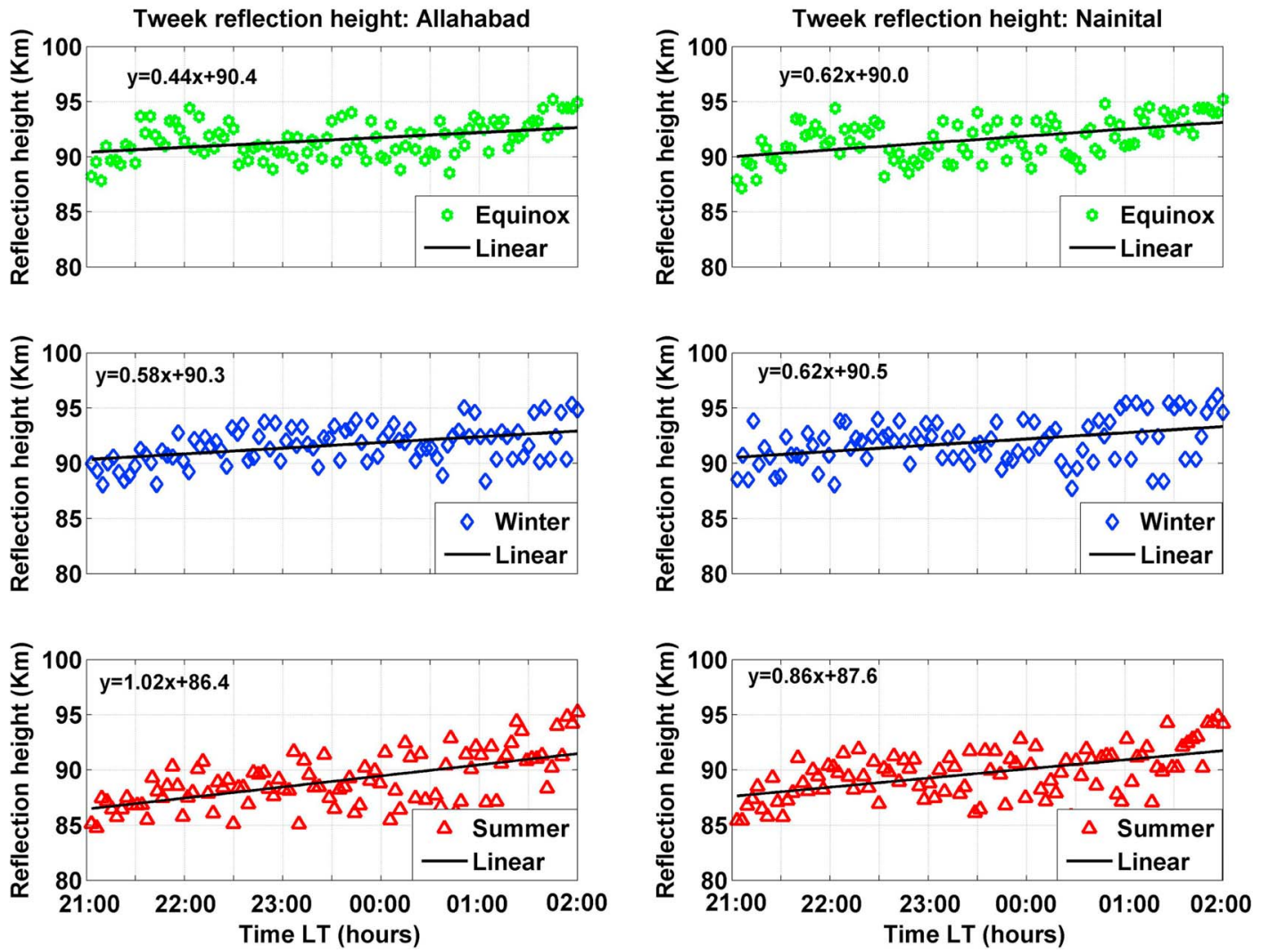

Figure 2. Variation in the reflection height estimated from first mode cutoff frequency of 990 tweeks simultaneously recorded at Allahabad and Nainital in pure nighttime 21:00-02:00 LT (15:30-20:30 UT) conditions. The trend of variation in the reflection height is shown by the linear fit lines and equations.

[16] The $h$ and $n_{e}$ at $h$ calculated for all modes of tweeks shown in Figure 1 using equations (1) and (2) are given in Table 2 (method 2). From the Table 2, it can be noted that higher modes of any tweek are reflected comparatively from higher altitude (about $1-3 \mathrm{~km}$ for $m=1-5$ ) with fundamental mode $(m=1)$ being reflected from lowest height. The results are consistent with the earlier findings of Shvets and Hayakawa [1998] and Kumar et al. [2008]. Theoretically, for a waveguide with perfectly conducing boundaries, the higher modes also should have been reflected from same altitude. Since the real EIWG is not perfectly conducing rather $\mathrm{D}$ region forms a diffuse boundary of which conductivity/ionization increases exponentially with the altitude, the higher modes are reflected from slightly higher altitudes as compared to lower modes. Further the estimated values of mean cutoff frequency $\left(f_{c m} / m\right)$ (as shown in Table 2) are slightly less for higher modes of tweek as compared to lower modes of same tweek. The electron density estimated from cutoff frequencies of first five modes of tweek shown in Figure 1a varies from 23 to $112 \mathrm{~cm}^{-3}$ in the altitude range of about $1.7 \mathrm{~km}(89.9-91.5 \mathrm{~km})$. The electron density for second mode is almost double to that obtained from first mode and so on for higher modes. The modes are reflected from the altitude where plasma frequency equals the cutoff frequency for that particular mode [Shvets and Hayakawa, 1998] which for higher modes happens where electron density (plasma frequency) and reflection height are higher. Since the electron density of the $\mathrm{D}$ region increases exponentially, the reflection height for higher modes increases accordingly. Shvets and Hayakawa [1998] from the cutoff frequency of modes $m=$ 1-8 of tweeks observed during low solar activity months (January-April 1991) found an increase in the electron density from 28 to $224 \mathrm{~cm}^{-3}$ in the altitude range of about $2 \mathrm{~km}$ at an altitude of $88 \mathrm{~km}$. Thus tweek method is useful in studying the variation in the electron density of the nighttime D region ionosphere over a limited altitude range of about 1 $2 \mathrm{~km}$ but requires clear multimode tweeks with at least three modes. The tweeks with higher modes $(m>3)$ occur less frequently because of higher attenuation for the higher modes [Kumar et al., 2008; Maurya et al., 2012]. To overcome with height limitation of method 2 and less occurrence of tweeks with higher modes $(m \geq 3)$ tweeks, method 3, which gives $h^{\prime}$ and $\beta$, has been utilized to estimate electron density and results are described in the section 4.3. Since frequency

Table 1. Seasonal Maximum and Minimum Values of the Reflection Height at Allahabad and Nainital During 2010

\begin{tabular}{lccccc}
\hline & \multicolumn{2}{c}{$\begin{array}{c}\text { Allahabad Tweek } \\
\text { Reflection }(\mathrm{km})\end{array}$} & & \multicolumn{2}{c}{$\begin{array}{c}\text { Nainital Tweek Reflection } \\
(\mathrm{km})\end{array}$} \\
\cline { 2 - 3 } \cline { 5 - 6 } Seasons & Minimum & Maximum & & Minimum & Maximum \\
\hline Summer & 84 & 96 & & 85 & 96 \\
Winter & 87 & 95 & & 88 & 95 \\
Equinox & 87 & 95 & & 86 & 94 \\
\hline
\end{tabular}



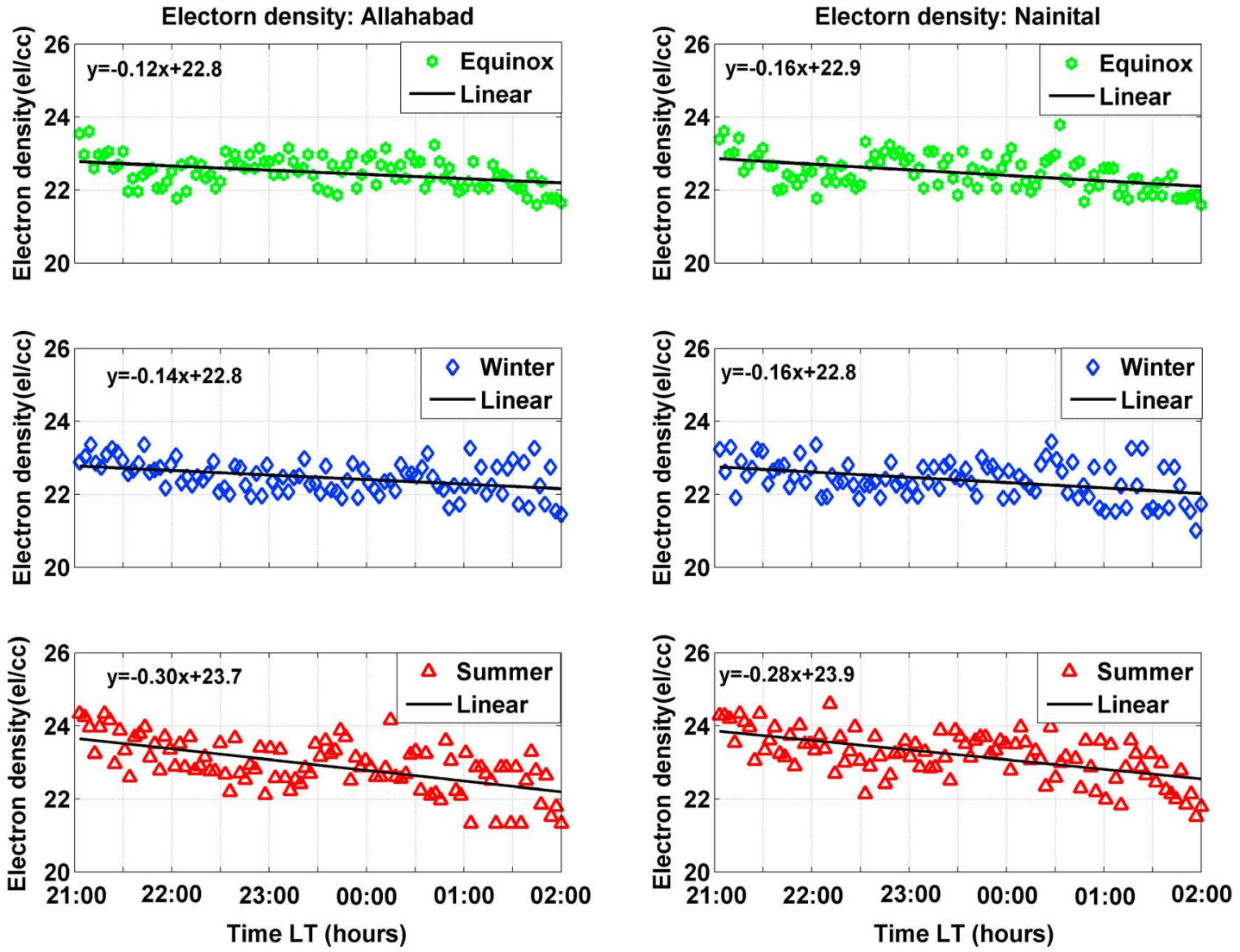

Figure 3. Variation in the electron density estimated from first mode cutoff frequency of 990 tweeks simultaneously recorded at Allahabad and Nainital in pure nighttime 21:00-02:00 LT (15:30-20:30 UT) propagation. The trend of variation in the electron density is shown by the linear fit lines and equations.

estimation of $25.8 \mathrm{kHz}$ can lead the error up to $\sim 1.5 \mathrm{~km}$ in the reflection height, the average values of $h^{\prime}$ and $\beta$ for larger number ( $\sim 300$ in each season) of tweeks were used to minimize the error in estimation of variation of electron density with altitudes.

\subsection{The $\boldsymbol{h}^{\prime}$ and $\boldsymbol{\beta}$ Parameters Estimated From Tweeks}

[17] The lower ionosphere up to $100 \mathrm{~km}$ altitude [Wait and Spies, 1964] can be characterized by the reference height $h^{\prime}$ in $\mathrm{km}$ and the exponential sharpness factor $\beta$ in $\mathrm{km}^{-1}$ as considered by many researchers [e.g., Cummer et al., 1998; Cummer and Inan, 2000; Thomson et al., 2007; Kumar et al., 2009; Han and Cummer, 2010a]. We have used the method developed by Kumar et al. [2009] to estimate the values of $h^{\prime}$ and $\beta$ from first three modes of tweeks observed during summer, winter and equinox seasons. For this purpose we have selected two tweeks (total ten from five quiet days) at every $15 \mathrm{~min}$ interval (as recording was in synoptic mode with $1 \mathrm{~min}$ at each $15 \mathrm{~min}$ interval) in the period of 21:0002:00 LT on the five international quiet days of the months, January, March and June 2010. These months are taken as representative of winter, equinox and summer seasons. The method involves two steps; in first step the path integrated reflection height $h$ and the electron density $n_{e}$ are obtained using modes $m=1,2,3$ of tweeks (mostly using $m=1-2$ ) by equation (1) and (2) for each selected tweek during three seasons. The values of $n_{e}$ and $h$ thus obtained have been
Table 2. The Mode Number, Cutoff Frequency, Mean Cutoff Frequency, Ionospheric Reflection Height $h$, and Electron Density $n_{e}$ for Tweeks Shown in the Spectrogram for Modes $m=1-5$

\begin{tabular}{ccccc}
\hline $\begin{array}{c}\text { Mode } \\
(m)\end{array}$ & $\begin{array}{c}\text { Cutoff } \\
\text { Frequency } \\
(\mathrm{kHz})\end{array}$ & $\begin{array}{c}\text { Mean Cutoff } \\
\text { Frequency } \\
(\mathrm{kHz})\end{array}$ & $\begin{array}{c}\text { Reflection } \\
\text { Height } \\
(\mathrm{km})\end{array}$ & $\begin{array}{c}\text { Electron } \\
\text { Density } \\
\left(\mathrm{cm}^{-3}\right)\end{array}$ \\
\hline \multicolumn{5}{c}{ Allahabad Station } \\
(a) & 1.6693 & 1.6693 & 89.9 & 23.20 \\
& 3.3212 & 1.6606 & 90.3 & 46.16 \\
& 4.9546 & 1.6515 & 90.8 & 68.87 \\
& 6.5839 & 1.6460 & 91.0 & 91.52 \\
& 8.1933 & 1.6387 & 91.5 & 113.89 \\
(b) & & & & \\
& 1.6159 & 1.6159 & 92.8 & 22.46 \\
& 3.1918 & 1.5959 & 94.0 & 44.37 \\
& 4.7843 & 1.5948 & 94.1 & 66.50 \\
& 6.3168 & 1.5792 & 95.0 & 87.80 \\
& & & & \\
(c) & & Nainital Station & & \\
& & & & \\
& 1.6693 & 1.6693 & 89.9 & 23.20 \\
& 3.2986 & 1.6493 & 90.9 & 45.85 \\
& 4.9813 & 1.6604 & 90.3 & 69.24 \\
(d) & 6.6374 & 1.6593 & 90.4 & 92.26 \\
& & & & \\
& 1.6159 & 1.6159 & 92.8 & 22.46 \\
& 3.1651 & 1.5825 & 94.8 & 44.00 \\
& 4.7943 & 1.5981 & 93.9 & 66.64 \\
& 6.3128 & 1.5782 & 95.1 & 87.75 \\
\hline
\end{tabular}


h' \& $\beta$ variation for Allahabad

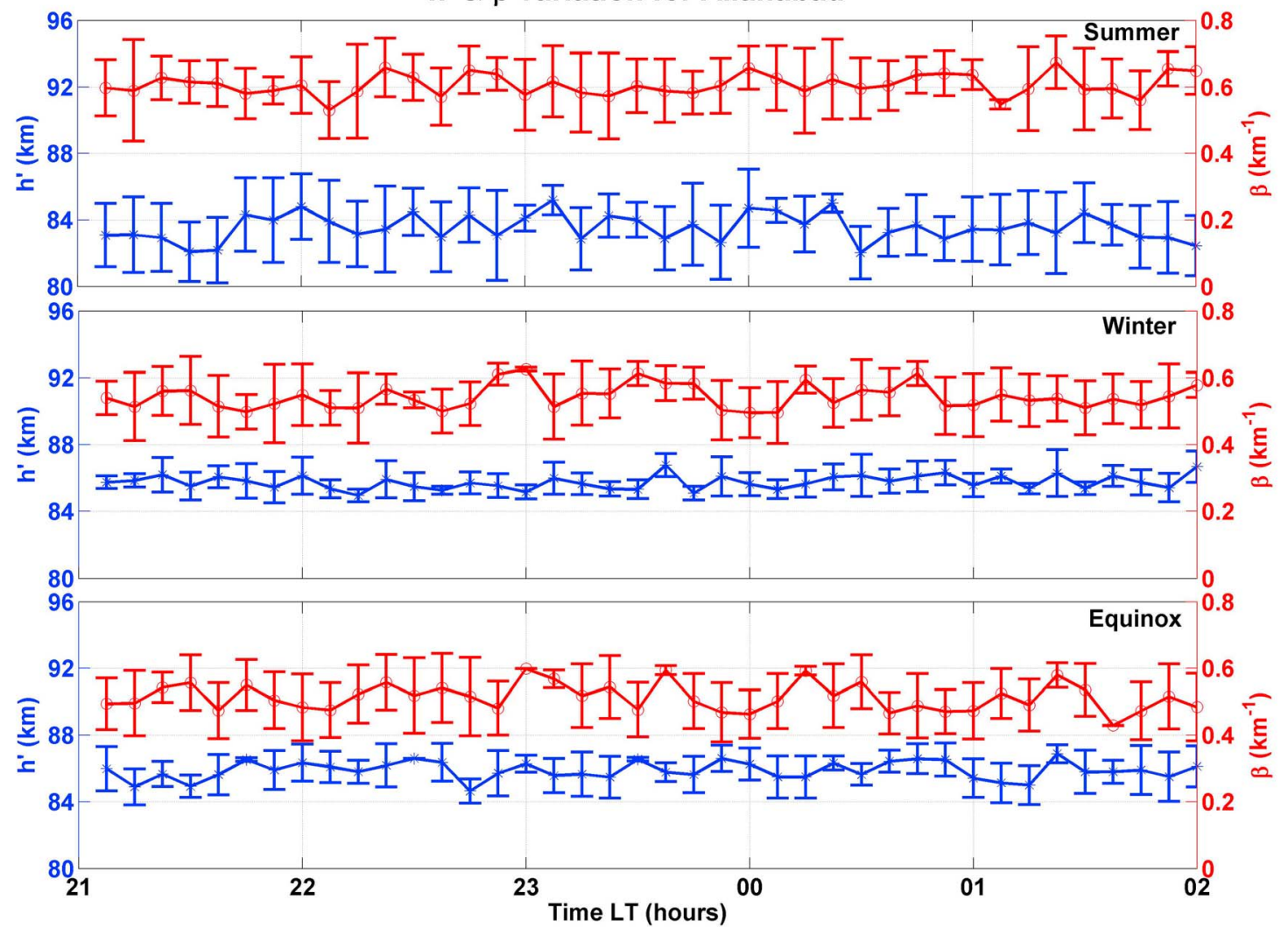

Figure 4. Variations of the nighttime ionospheric D region parameters, reference height $h^{\prime}$, and sharpness factor $\beta$ during three seasons summer, winter, and equinox at Allahabad.

used to calculate the values $h^{\prime}$ and $\beta$ using equation (5) as described by Kumar et al. [2009]. The average values of $h^{\prime}$ and $\beta$ on five quiet days thus obtained for Allahabad and Nainital during winter, summer and equinox are shown in Figures 4 and 5 . The bars indicate the standard deviation. The estimated values of $h^{\prime}$ and $\beta$ are nearly same at both the stations for the same season. However, there is a considerable day-to-day variability in $h^{\prime}$ and $\beta$ of about $5 \mathrm{~km}$ and $0.2 \mathrm{~km}^{-1}$, respectively, which at any hour could be in the range of $4 \mathrm{~km}$ and $0.18 \mathrm{~km}^{-1}$. Seasonally, variability in $h^{\prime}$ is more during summer as compared to winter and equinox. The $h^{\prime}$ during summer at Allahabad varies $82.04-85.18 \mathrm{~km}$ with standard deviation (SD) \pm 1.58 to $\pm 0.88 \mathrm{~km}$ and at Nainital it varies $82.08-84.30 \mathrm{~km}$ with $\mathrm{SD} \pm 1.17$ to $\pm 1.49 \mathrm{~km}$. During winter $h^{\prime}$ varies $84.64-86.88 \mathrm{~km}$ with SD \pm 0.73 to $\pm 0.54 \mathrm{~km}$ at Nainital and at Allahabad $h^{\prime}$ varies $85.36-86.88 \mathrm{~km}$ with $\mathrm{SD} \pm 0.93$ to $\pm 0.76 \mathrm{~km}$. During equinox $h^{\prime}$ varies $84.9-86.77 \mathrm{~km}$ with $\mathrm{SD} \pm 0.37$ to $\pm 0.69 \mathrm{~km}$ at Allahabad and $84.86-86.30 \mathrm{~km}$ with $\mathrm{SD} \pm 0.82$ to $\pm 0.38 \mathrm{~km}$ at Nainital. The nighttime $\beta$ during summer, winter and equinox varies between $0.53-0.67 \mathrm{~km}^{-1}$ with $\mathrm{SD} \pm 0.085$ to $\pm 0.078 \mathrm{~km}^{-1}, 0.43-0.60 \mathrm{~km}^{-1}$ with $\mathrm{SD} \pm 0.002$ to $\pm 0.042 \mathrm{~km}^{-1}$ and $0.50-0.63 \mathrm{~km}^{-1}$ with $\mathrm{SD} \pm 0.074$ to $\pm 0.005 \mathrm{~km}^{-1}$, respectively, at Allahabad and between $0.54-0.68 \mathrm{~km}^{-1}$ with $\mathrm{SD} \pm 0.01$ to $\pm 0.057 \mathrm{~km}^{-1}, 0.46-$ $0.59 \mathrm{~km}^{-1}$ with SD \pm 0.08 to $\pm 0.04 \mathrm{~km}^{-1}$ and $0.48-0.60 \mathrm{~km}^{-1}$ with $\mathrm{SD} \pm 0.063 \mathrm{~km}^{-1}$ to $\pm 0.040 \mathrm{~km}^{-1}$, respectively, at Nainital. The variability is less during equinox and winter seasons at both the stations. The average estimated values of $h^{\prime}$ and $\beta$ for each season at both the stations are given in Table 3. Table 3 shows that $h^{\prime}$ and $\beta$ are same at both stations. Seasonally, $h^{\prime}$ and $\beta$ are same during winter and equinox but $h^{\prime}$ is lower and $\beta$ is higher during summer.

[18] There is only one previous study on $h^{\prime}$ and $\beta$ parameters estimated using tweek method by Kumar et al. [2009]. Kumar et al. [2009] used tweek radio atmospheric observed at a low latitude in the South Pacific Region and found $h^{\prime}$ and $\beta$ to be $83.1 \mathrm{~km}$ and $0.63 \mathrm{~km}^{-1}$, respectively, during low solar activity period $\left(R_{z} \sim 15\right)$ between March to December 2006. Our values of $h^{\prime}$ and $\beta$ shown in Table 3 match well with those of Kumar et al. [2009] during summer, but are higher during other two seasons. Cummer et al. [1998] using LWPC modeling of different ionospheres for VLF sferics observed during low solar activity month of July 1996 estimated nighttime values of $h^{\prime}$ and $\beta 83.3 \mathrm{~km}$ and $0.49 \mathrm{~km}^{-1}$, respectively. Our value of $\beta$ is higher up to $0.11 \mathrm{~km}^{-1}$ than that obtained by Cummer et al. [1998]. Cheng et al. [2006] used similar procedure as used by Cummer et al. [1998] for sferics observed during 16 summer nights from 1 July to 4 August 2004 and obtained $h^{\prime}$ and $\beta$ values in the range $83.6-85.6 \mathrm{~km}$ and $0.40-0.50 \mathrm{~km}^{-1}$, respectively. Using sferics recorded during July-August 2005 in the nighttime, Han and Cummer [2010a] estimated hourly $h^{\prime}$ between $82.0 \mathrm{~km}$ and $87.2 \mathrm{~km}$ with mean value of $84.9 \mathrm{~km}$ and standard deviation of $1.1 \mathrm{~km}$. Our results on $h^{\prime}$ are in good agreement with results reported by Han and Cummer [2010a]. Thomson et al. [2007] using LWPC modeling of phase and amplitude of VLF narrowband 


\section{$h^{\prime} \& \beta$ variation for Nainital}
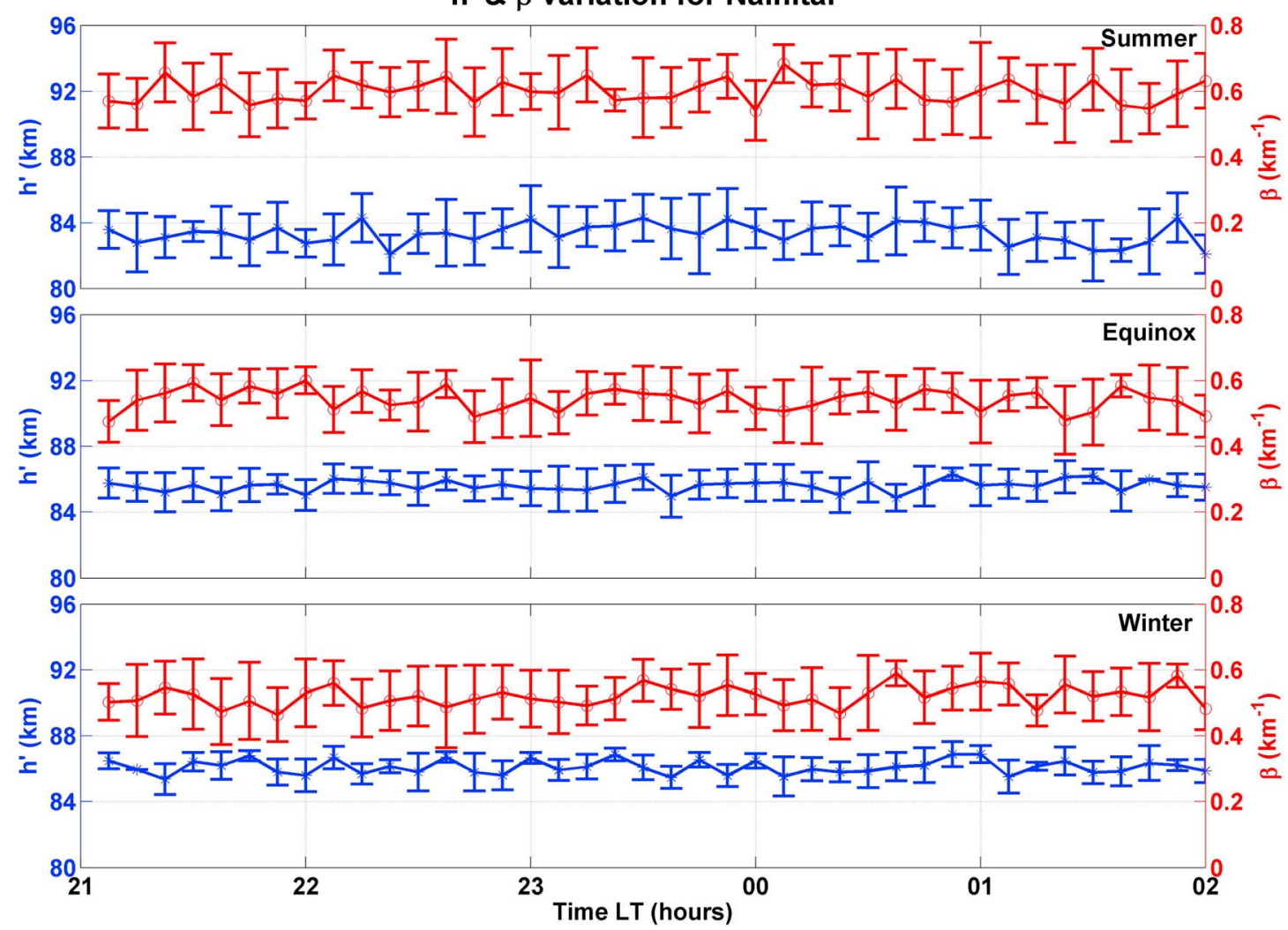

Figure 5. Variations of the nighttime ionospheric D region parameters, reference height $h^{\prime}$, and sharpness factor $\beta$ during three seasons summer, equinox, and winter at Nainital.

transmitter signals determined nighttime values of $h^{\prime}=85.1 \pm 0.4 \mathrm{~km}$ and $\beta=0.63 \pm 0.04 \mathrm{~km}^{-1}$ for the mid latitude $\mathrm{D}$ region near solar minimum. Thomson and McRae [2009] using LWPC modeling estimated $h^{\prime}$ and $\beta$ to be 85.1 $\mathrm{km}$ and $\beta=0.63 \mathrm{~km}^{-1}$, respectively, for equatorial and nonequatorial VLF paths. The advantage of estimation of $h^{\prime}$ and $\beta$ using tweeks over narrowband signal modeling is the larger geographic area covered around the observational site.

\subsection{Equivalent Electron Density Profile and Comparison With IRI-2007 and Rocket Measurements}

[19] Tweek method utilized here gives path integrated electron density and reflection height. We have estimated average values of nighttime $h^{\prime}$ and $\beta$, for summer, winter and equinox seasons. The values of $h^{\prime}$ and $\beta$ estimated for each season are employed in equation (5) to calculate electron density profile in the altitude range of 80-100 km. Electron density calculated by tweek method has been compared with that obtained using IRI-2007 model and past Rocket measurements available in the Indian region.

\subsubsection{Comparison With IRI-2007 Model}

[20] The IRI-2007 model gives electron density profile until year 2009 only. We have obtained electron density for the location of Allahabad and Nainital at 00:00 LT on five international quiet days during January, March and June of 2009. Since there is no difference in the solar activity level during 2009 and 2010, we take electron density during 2009 as the representative of 2010 . IRI-2007 model shows no significant difference in the electron density profile for Allahabad and
Nainital during summer, winter and equinox seasons and also no significant seasonal variation in the electron density profile at these stations. However, the values of $h^{\prime}$ and $\beta$ obtained from tweek analysis and hence the electron density profile for summer is different than those for winter and equinox at both the stations. As shown in Figure 6a, during winter season electron density obtained from tweek method varies in the range of $4-6194 \mathrm{~cm}^{-3}$ in the altitude range of $80-100 \mathrm{~km}$. Also the electron density thus obtained is quite comparable to electron density obtained from IRI-2007 in the altitude range of $91-95 \mathrm{~km}$ with a very good match at $94 \mathrm{~km}$ altitude but it is significantly low at the lower altitudes (Figure 6). The electron density obtained from tweek method during summer season (Figure 6b) varies in the range of $10-95476 \mathrm{~cm}^{-3}$ in the altitude range of 80-100 km and shows a good comparison with IRI-2007 in the altitude range of $82-89 \mathrm{~km}$ with very good match at $88 \mathrm{~km}$. The electron density variation during the equinox (Figure 6c) is very much similar to that during winter

Table 3. Seasonal Average Values of Reference Height $h^{\prime}$ and Sharpness Factor $\beta$ for Allahabad and Nainital During 2010

\begin{tabular}{lccccc}
\hline & \multicolumn{2}{c}{ Allahabad } & & \multicolumn{2}{c}{ Nainital } \\
\cline { 2 - 3 } \cline { 5 - 6 } Seasons & $h^{\prime}(\mathrm{km})$ & $\beta\left(\mathrm{km}^{-1}\right)$ & & $h^{\prime}(\mathrm{km})$ & $\beta\left(\mathrm{km}^{-1}\right)$ \\
\hline Summer & 83.54 & 0.61 & 83.35 & 0.60 \\
Winter & 85.87 & 0.51 & & 86.10 & 0.52 \\
Equinox & 85.74 & 0.54 & & 85.60 & 0.54 \\
\hline
\end{tabular}


Tweek Analysis: Comparison with Rocket \& IRI 2007 Data

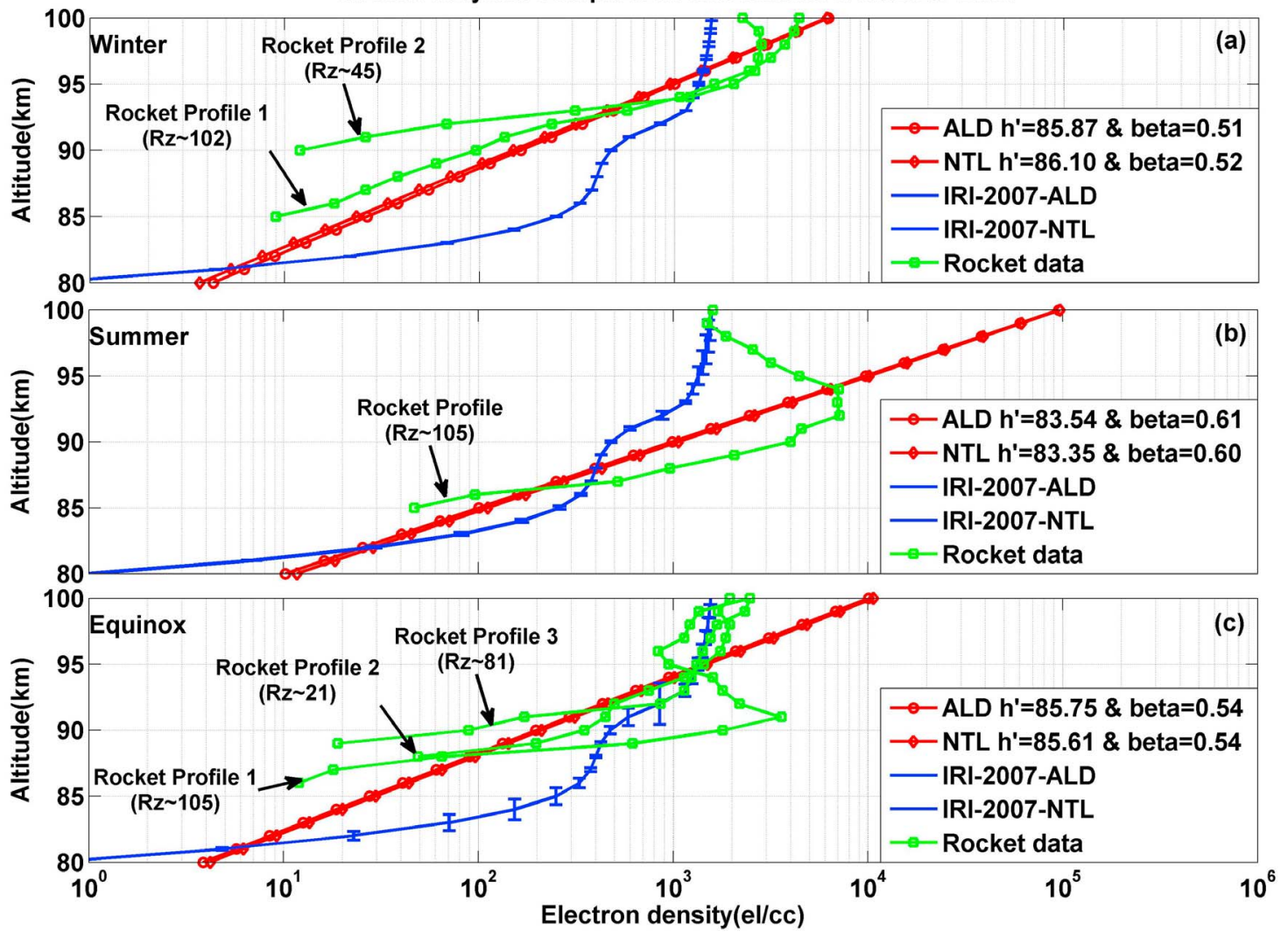

Figure 6. A comparison of electron density profiles of the D region obtained using tweek method, International Reference Ionosphere (IRI-2007) model, and rocket data during winter, summer, and equinox seasons. Error bars shown in IRI-2007 data are standard deviations.

with a very good agreement in the altitude range of $89-93 \mathrm{~km}$. In general, equivalent electron density profile of the nighttime lower ionosphere using tweek method shows lower values of electron density by about 5-60\% than those obtained using IRI-2007 model at both the stations. Kumar et al. [2009] have shown that electron density using tweek method is lower by about $20-45 \%$ than those obtained using IRI-2001 model at a low-latitude station in the South Pacific Region. From the analysis of tweek atmospherics observed in Japan, Ohya et al. [2003] found tweek estimated electron density almost consistent with electron density profile obtained using IRI-95 model in the altitude range of $80-85 \mathrm{~km}$. The overall analysis shows that tweek method is useful for estimating the electron density profile of the nighttime D region ionosphere. Tweek method shows seasonal variation in the nighttime $\mathrm{D}$ region electron density whereas IRI-2007 model does not show significant seasonal variation. The results are consistent with IRI-2007 model in certain ranges of altitudes during different seasons.

\subsubsection{Comparison With Rocket Data}

[21] Rocket data provides a direct measurement of electron density of the lower ionosphere. Rocket experiment for the $\mathrm{D}$ region electron density measurement at a low latitude, Thumba, an Equatorial Rocket Launching Station (geographic latitude, $8^{\circ} 32^{\prime} \mathrm{N}$, magnetic dipole, $0^{\circ} 24^{\prime} \mathrm{S}$ ), in the Indian region, was carried out using Langmuir probe method on different types of rockets. The results of extensive series of measurements of lower ionospheric electron density at Thumba made under various solar and geographical conditions have been reported by Subbaraya et al. [1983]. We have selected nighttime rocket electron density data on 2 February 1968 at 18:56 Indian Standard Time $\left(82.5^{\circ} \mathrm{E}\right)$ (IST) (sunspot number $R_{z} \sim 102$ ) and on 3 February1973 at 00:30 IST $\left(R_{z} \sim 48\right)$ for winter, on 29 August 1968 at 22:30 IST $\left(R_{z} \sim 105\right)$ for summer and on 15 March 1975 at 22:04 IST $\left(R_{z} \sim 21\right)$, on 12 March 1967 at 22:30 IST $\left(R_{z} \sim 81\right)$, on 21 April 1975 at 23:00 IST $\left(R_{z} \sim 18\right)$ for equinox season [Subbaraya et al., 1983]. During winter season, the trend of variation of electron density by tweek method is similar to rocket profile 1 in the altitude range of 86-98 km, and in the altitude range of $93-98 \mathrm{~km}$ for profile 2 . The electron density is higher by about $30-52 \%$ in the altitude range of $86-94 \mathrm{~km}$ and lower by about $2-20 \%$ in the altitude range of 96-98 km with a good match in the range of 94-96 km. Similarly electron density is lower by about $3-40 \%$ in the altitude range of 96-98 km with good match at $95 \mathrm{~km}$ as compared to rocket profile 2. During summer season, the electron density measured by rockets varies consistently with the electron density estimated by tweek method in the altitude range of $87-93 \mathrm{~km}$ with a difference of about $15-58 \%$. For equinox season, electron density is available for three rocket profiles only which vary concurrently with electron density profile estimated by tweek method in the altitude range of 89-94 km, 92-94 km, 92-95 km but with lower/higher values by $32-68 \%, 2-55 \%$ and $6-65 \%$, respectively. The difference in the electron density is due to the fact that some of the rocket experiments were conducted during high solar 
activity period. Overall the trend of variation of electron density calculated by tweek method is consistent with available rocket electron density profiles in the altitude range of $86-98 \mathrm{~km}$ with a difference in electron density of about 2 $68 \%$ during different seasons. Seasonal variation in the electron density estimated by tweek method is consistent with the seasonal variation observed with the rocket experiments [Gupta, 1998]. The electron density estimated by all three techniques is consistent in the altitude range of 82-98 $\mathrm{km}$ indicating that tweek method is also useful for obtaining electron density profile of the nighttime $\mathrm{D}$ region.

[22] Thomson et al. [2007] estimated the nighttime electron density of about $40 \mathrm{~cm}^{-3}$ generated by Lyman $\alpha$ of geocorona at the altitude of $85 \mathrm{~km}$ which is higher compared to our tweek measurements $\left(27 \mathrm{~cm}^{-3}\right.$ during winter and $28 \mathrm{~cm}^{-3}$ during equinox) as shown in Figure 6. The main sources of day-to-day and temporal variability of the nighttime $\mathrm{D}$ region electron density and $h^{\prime}$ and $\beta$ have been explained in section 4.2. The variations can also be due to the presence of metal ions $\left(\mathrm{Fe}^{+}, \mathrm{Mg}^{+}\right)$, probably of meteor origin, which are left out from the daytime ionization, because of slow recombination rate. The electron density due to metal ions has been reported $\sim 10^{3} \mathrm{~cm}^{-3}$ at $90 \mathrm{~km}$ altitude [Aikin and Goldberg, 1973; Kopp , 1997]. This at least partially explains the higher electron density of $1000 \mathrm{~cm}^{-3}$ estimated during summer at $90 \mathrm{~km}$ as compared to the electron density during winter and equinox seasons at the same altitude which is $170 \mathrm{~cm}^{-3}$ and $200 \mathrm{~cm}^{-3}$, respectively. Other factor which can contribute to variation in the nighttime electron density at different altitudes is possibly the formation of water cluster ions below $85 \mathrm{~km}$ [Reid, 1977]. The electrons recombine very rapidly with these cluster ions and electron density falls rapidly with decreasing height. Thomson and McRae [2009] suggested that irregularities in the equatorial electrojet may be associated with gradient drift instabilities and can penetrate nighttime $\mathrm{D}$ region ionosphere down up to $90 \mathrm{~km}$ altitude and cause the scattering of VLF waves on passing over equator and can contribute to the variability in $h^{\prime}$ and $\beta$. Lower ionospheric temperature variation caused by the presence of atmospheric waves [Sugiyama, 1988] can also cause the variation in the electron density; however, there is no direct observation of atmospheric waves in our tweek data.

\subsection{Estimation of Locations of Causative Lightning Sources of Tweeks}

[23] Since tweek method gives the path integrated reflection height and electron density at the reflection height, it is also important to find the locations of tweek causative lightnings and hence the propagations paths over which the reflection height and the electron densities are obtained. There are two techniques widely used for lightning detection; multi station technique [Ohya et al., 2003] and single station technique [Ramachandran et al., 2007]. We have used multi station technique (two station) developed by Ohya et al. [2003] for simultaneously recorded 1008 pairs (2016 total) clear and long-duration tweeks at Allahabad and Nainital during one year period from January to December 2010, in the pure nighttime (21:00-02:00 LT, or 15:30-20:30 UT), to locate the causative lightnings of tweeks. The propagation distances $d$ of these simultaneously recorded tweeks to both the stations were calculated using equation (4) and circles of those radii with center at the location of stations were drawn. The location of causative lightning of any tweek was determined by the intersection of two circles corresponding to the propagation distance of same tweek to Allahabad and Nainital. The locations of intersection points were matched with the World-Wide Lightning Location Network (WWLLN) lightning data. The WWLLN is the worldwide lightning location network in which 40 universities and research institutions are currently participating worldwide. It detects global lightnings with return stroke currents $>50 \mathrm{kA}$ with spatial and temporal accuracy of about $10 \mathrm{~km}$ and $10 \mu \mathrm{s}$, respectively, with global detection efficiency less than $4 \%$ [Rodger et al., 2006]. However, with the increase in the number of stations its detection efficiency has improved up to $10 \%$. The WWLLN detected the causative lightings for 277 (27.5\%) tweeks out of total 1008 tweeks as shown by the overlap of red circles (WWLLN detected lightnings) over green circles (locations estimated using two station tweek observation method). From Figure 7 we can see that causative lightning sources of tweeks were located in the wide range but majority of them $(\sim 65 \%)$ were in the Southeast Asian region $\left(20-10^{\circ} \mathrm{N}, 75-130^{\circ} \mathrm{E}\right)$. Figure 7 also gives the comparison of lightning source positions calculated by tweek method (green circle) with those detected by the WWLLN (red circles) for winter, summer and equinox, respectively. In Figure 7 we have also drawn three circle of radius 1000, 3000 , and $5000 \mathrm{~km}$ to show the causative source lightning distances with respect to the receiving site Allahabad. Most of the tweeks propagated more than $1000 \mathrm{~km}$ and about $60 \%$ tweeks propagated in the range of 3000-5000 km.

[24] The direction finding technique applied here shows that most tweeks observed in the Indian sector come from south East Asian region, which is one of the most lighting activity regions of the world [Christian et al., 2003]. The dayto-day variability in $h^{\prime}$ and $\beta$ estimated from tweeks shown in Figures 4 and 5 can also be caused by heating of the $D$ region by lighting discharges. Han and Cummer [2010a] found a good correlation between $h^{\prime}$ and the rate of lightning strokes. They have concluded that either direct lightning coupling to the ionosphere or ducted lightning-induced electron precipitation can drive significant $\mathrm{D}$ region variability on the time scales from minutes to hours. At our stations direct lightning coupling to the ionosphere producing short-term (10-100 s) significant electron density changes is most likely the source of day-to-day variability as lightning-induced electron precipitation is very unlikely to occur in the low-latitude region [Voss et al., 1998]. The direct energy coupling between lightning discharges and lower ionosphere causing short-term changes in the electron density or conductivity at the VLF reflection heights have been reported by many researchers [e.g., Inan et al., 1988; Rodger, 2003, and references therein]. The heating of lower ionosphere by strong quasi-electrostatic field generated by strong lightnings causes the conductivity enhancements [e.g., Pasko et al., 1995; Inan et al., 1996; Inan et al., 2010] and the electromagnetic pulses from cloud-to-ground and/or successive in-cloud lightning discharges associated with cloud-to-ground discharges can produce appreciable electron density changes which could be 


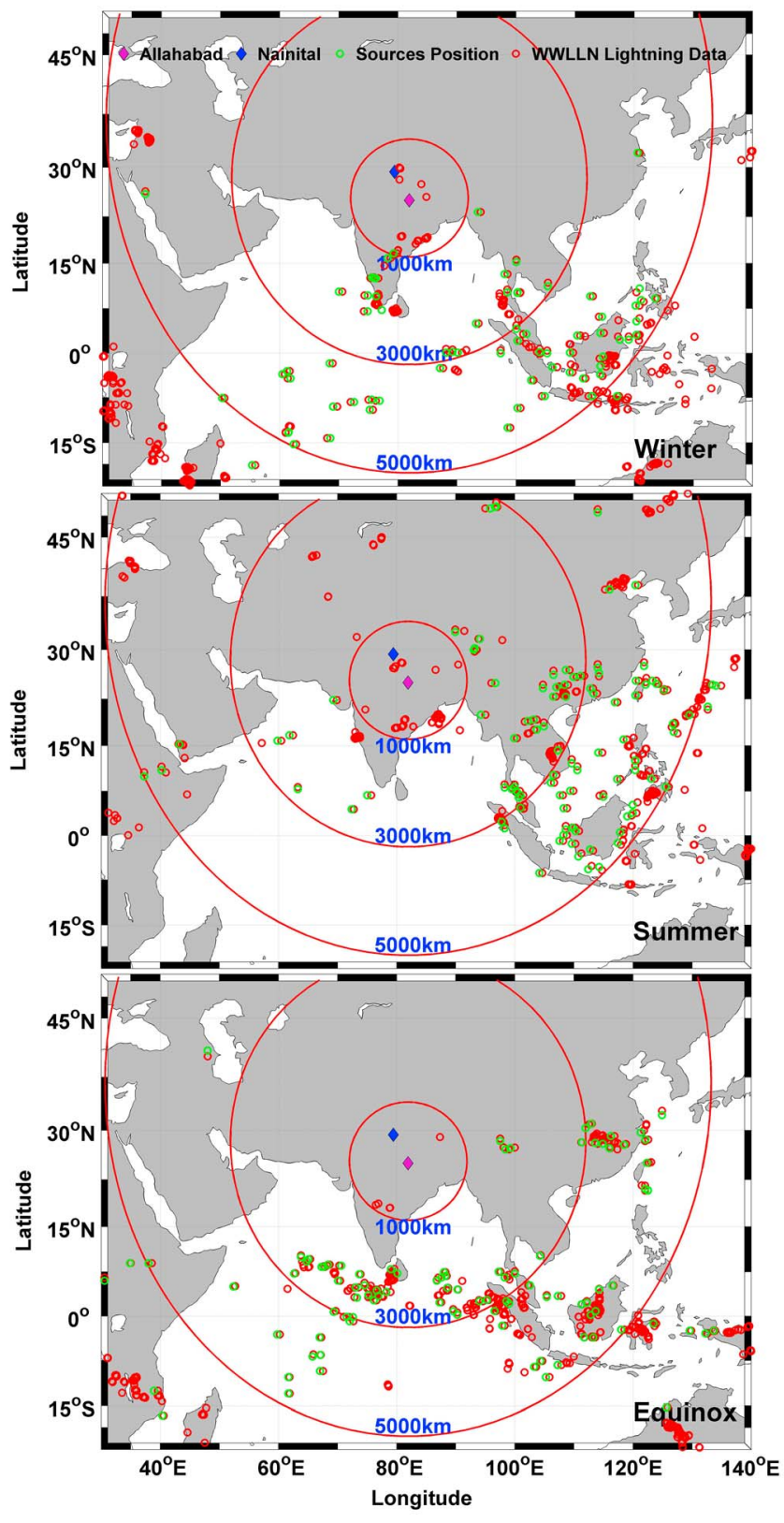

Figure 7. Locations of tweek causative lightning discharges determined by tweek method (green color) simultaneously at Allahabad and Nainital during winter, summer, and equinox seasons of 2010. The World-Wide Lightning Location Network (WWLLN) detected lightning locations are indicated in red color.

the electron density enhancements/reductions at the VLF reflection height [Inan et al., 1993; Rodger et al., 2001; Marshall et al., 2008].

\section{Summary and Conclusions}

[25] The dispersed sferics called tweeks observed using Stanford University designed AWESOME VLF receiver system installed at Allahabad and Nainital during one year period January to December 2010 were analyzed for the pure nighttime 21:00-02:00 LT (15:30-20:30 UT) propagation. The simultaneously observed tweeks at both the stations were used to estimate the path integrated tweek reflection heights and electron densities at the reflection heights. For the first time nocturnal and seasonal variations of the nighttime Wait ionospheric parameters $\left(h^{\prime}\right.$ and $\left.\beta\right)$ have been studied by using tweeks observed at the low-latitude stations Allahabad and Nainital, in the Indian region. The average values of $h^{\prime}$ and $\beta$ for seasons summer, winter and equinox have been estimated to obtain the seasonal electron density profile of the $\mathrm{D}$ region and compared with IRI-2007 model and earlier rocket measurements in India. The main findings of the study can be concluded as

[26] 1 . The path integrated reflection height $h$ of nighttime D region ionosphere calculated by using first-order cutoff frequency of tweeks varies in the range $87-95 \mathrm{~km}$ at both the stations. The path integrated electron density $n_{e}$ estimated using first-order cutoff frequency of tweeks varies as 21 $24.5 \mathrm{~cm}^{-3}$ at Allahabad and $21.5-24 \mathrm{~cm}^{-3}$ at Nainital.

[27] 2. The nocturnal and seasonal variability in the $h^{\prime}$ and $\beta$ at both the stations shows that the nighttime $\mathrm{D}$ region is far from static. The average values of $h^{\prime}$ and $\beta$ for both the stations are almost same $\left(86.1-85.6 \mathrm{~km}\right.$, and $\left.0.51-0.54 \mathrm{~km}^{-1}\right)$ during winter and equinox seasons. The $h^{\prime}$ is lower by $2-3 \mathrm{~km}$ and $\beta$ is higher by $0.07-0.09 \mathrm{~km}^{-1}$ during summer as compared to winter and equinox seasons.

[28] 3. The day-to-day variability in $h$ is about $8-9 \mathrm{~km}$ with temporal variability of $1-2 \mathrm{~km}$ in any $1 \mathrm{~h}$ duration. The dayto-day variability in $h^{\prime}$ is about $4-5 \mathrm{~km}$ and in $\beta$ it is about $0.1-0.25 \mathrm{~km}^{-1}$. The $n_{e}$ obtained using tweek method shows lower values than those obtained using IRI-2007 model and higher during winter and equinox and lower during summer when compared with Rocket data, however, the trend of $n_{e}$ variation in the altitude range of $85-98 \mathrm{~km}$ is almost the same. This shows that tweek method is one of the useful methods for estimating the electron density profile of the nighttime $\mathrm{D}$ region ionosphere.

[29] 4. The $n_{e}$ obtained using tweek method shows seasonal variation with higher values during summer as compared to winter and equinox seasons but IRI-2007 model does not show any seasonal variation.

[30] 5. The locations of causative lightnings obtained using tweek method and compared with WWLLN detected lightings show that the lightning sources of most tweeks were located in the Asia Oceanic region. The WWLLN detected about $27.5 \%$ of lightings associated with tweeks.

[31] Acknowledgments. The authors from the Indian Institute of Geomagnetism (IIG) are grateful to the Director, IIG, for support and encouragement to carry out the project and work. All authors thank the International Space Weather Initiative Program (ISWI) and the United Nations Basic Space Sciences Initiative (UNBSSI) program for their support. Thanks to CAWSES India, Phase-II program for the financial support in the form of a project to carry out VLF research activities at IIG.

[32] Robert Lysak thanks the reviewers for their assistance in evaluating this paper.

\section{References}

Aikin, A. C., and R. A. Goldberg (1973), Metallic ions in the equatorial ionosphere, J. Geophys. Res., 78(4), 734-745, doi:10.1029/JA078i004p00734.

Bainbridge, G., and U. S. Inan (2003), Ionospheric $D$ region electron density profiles derived from the measured interference pattern of VLF waveguide modes, Radio Sci., 38(4), 1077, doi:10.1029/2002RS002686.

Budden, K. G. (1961), The Wave-Guide Mode Theory of Wave Propagation, Logos, London. 
Cheng, Z., S. A. Cummer, D. N. Baker, and S. G. Kanekal (2006), Nighttime $D$ region electron density profiles and variability inferred from broadband measurement using VLF radio emission from lightning, J. Geophys. Res., 111, A05302, doi:10.1029/2005JA011308.

Christian, H. J., et al. (2003), Global frequency and distribution of lightnings as observed from spoace by the Optical transient Detector, J. Geophys. Res., 108(D1), 4005, doi:10.1029/2002JD002347.

Cohen, M. B., U. S. Inan, and E. W. Paschal (2010), Sensitive broadband ELF/VLF radio reception with the AWESOME instrument, IEEE Trans. Geosci. Remote Sens., 48(1), 3-7, doi:10.1109/TGRS.2009.2028334.

Cummer, S. A., and U. S. Inan (2000), Ionospheric $E$ region remote sensing with ELF radio atmospheric, Radio Sci., 35, 1437-1444, doi:10.1029/ 2000RS002335.

Cummer, S. A., U. S. Inan, and T. F. Bell (1998), Ionospheric $D$ region remote sensing using VLF radio atmospherics, Radio Sci., 33(6), 1781-1792, doi:10.1029/98RS02381.

Davies, K. (1990), Ionospheric Radio, Peregrinus, London, doi:10.1049/ PBEW031E.

Ferencz, C. (2004), Real solution of monochromatic wave propagation in inhomogeneous media, Pramana, 62, 943-955, doi:10.1007/BF02706142.

Ferencz, O. E., C. Ferencz, P. Steinbach, J. Lichtenberger, D. Hamar, M. Parrot, F. Lefeuvre, and J.-J. Berthelier (2007), The effect of subionospheric propagation on whistlers recorded by the DEMETER satelliteobservation and modeling, Ann. Geophys., 25, 1103-1112, doi:10.5194/ angeo-25-1103-2007.

Friedrich, M., and K. M. Torkar (2001), FIRI: A semiempirical model of the lower ionosphere, J. Geophys. Res., 106(A10), 21,409-21,418, doi:10.1029/2001JA900070.

Gupta, S. P. (1998), Diurnal and seasonal variations of D-region electron density at low latitude, Adv. Space Res., 21(6), 875-881, doi:10.1016 S0273-1177(97)00646-7.

Han, F., and S. A. Cummer (2010a), Midlatitude nighttime D region ionosphere variability on hourly to monthly time scales, J. Geophys. Res., 115, A09323, doi:10.1029/2010JA015437.

Han, F., and S. A. Cummer (2010b), Midlatitude daytime D region ionosphere variations measured from radio atmospherics, J. Geophys. Res., 115, A10314, doi:10.1029/2010JA015715.

Han, F., S. A. Cummer, J. Li, and G. Lu (2011), Daytime ionospheric $D$ region sharpness derived from VLF radio atmospherics, J. Geophys. Res., 116, A05314, doi:10.1029/2010JA016299.

Hargreaves, J. K. (1992), The Solar-Terrestrial Environment, Cambridge Univ. Press, New York.

Hayakawa, M., K. Ohta, and K. Baba (1994), Wave characteristics of tweek atmospherics deduced from the direction-finding measurement and theoretical interpretation, J. Geophys. Res., 99, 10,733-10,743, doi:10.1029/ 93JD02555

Hayakawa, M., K. Ohta, S. Shimakura, and K. Baba (1995), Recent findings on VLF/ELF sferics, J. Atmos. Terr. Phys., 57, 467-477, doi:10.1016/0021-9169(94)00074-X.

Heaps, M. G. (1978), Parameterization of the cosmic ray ion-pair production rate above $18 \mathrm{~km}$, Planet. Space Sci., 26, 513-517, doi:10.1016/ 0032-0633(78)90041-7.

Igarashi, K., Y. Murayama, M. Nagayama, and S. Kawana (2000), D-region electron density measurements by MF radar in the middle and high latitudes, Adv. Space Res., 25, 25-32, doi:10.1016/S0273-1177(99)00893-5.

Inan, U. S., D. C. Shafer, W. Y. Yip, and R. E. Orville (1988), Subionospheric VLF signatures of nighttime $\mathrm{D}$ region perturbations in the vicinity of lightning discharges, J. Geophys. Res., 93, 11,455-11,472, doi:10.1029/JA093iA10p11455.

Inan, U. S., J. V. Rodriguez, and V. P. Idone (1993), VLF signatures of lightning-induced heating and ionization of the nighttime D-region, Geophys. Res. Lett., 20(21), 2355-2358, doi:10.1029/93GL02620.

Inan, U. S., S. C. Reising, G. J. Fishman, and J. M. Horack (1996), On the association of terrestrial gamma-ray bursts with lightning and implication for sprites, Geophys. Res. Lett., 23(9), 1017-1020, doi:10.1029/ 96GL00746.

Inan, U. S., S. A. Cummer, and R. A. Marshall (2010), A survey of ELF and VLF research on lightning-ionosphere interactions and causative discharges, J. Geophys. Res., 115, A00E36, doi:10.1029/2009JA014775.

Kopp, E. (1997), On the abundance of metal ions in the lower thermosphere, J. Geophys. Res., 102(A5), 9667-9674, doi:10.1029/97JA00384

Kumar, S., S. K. Dixit, and A. K. Gwal (1994), Propagation of tweek atmospherics in the Earth-ionosphere waveguide, Nuovo Cim., 17C, 275-281.

Kumar, S., A. Kishore, and V. Ramachandran (2008), Higher harmonic tweek sferics observed at low latitude: Estimation of VLF reflection heights and tweek propagation distance, Ann. Geophys., 26, 1451-1459, doi:10.5194/angeo-26-1451-2008.
Kumar, S., A. Deo, and V. Ramachandran (2009), Nighttime D-region equivalent electron density determined from tweek sferics observed in the South Pacific region, Earth Planets Space, 61, 905-911.

Maeda, K.-I. (1971), Study on electron density profile in the lower ionosphere, J. Geomagn. Geoelectr., 23, 133-159, doi:10.5636/jgg.23.133.

Marshall, R. A., U. S. Inan, and T. W. Chevalier (2008), Early VLF perturbations caused by lightning EPM-driven dissociative attachment, Geophys. Res. Lett., 35, L21807, doi:10.1029/2008GL035358.

Maurya, A. K., R. Singh, B. Veenadhari, P. Pant, and A. K. Singh (2010), Application of lightning discharge generated radio atmospherics/tweeks in lower ionospheric plasma diagnostic, J. Phys. Conf. Ser., 208, 012061, doi:10.1088/1742-6596/208/1/012061.

Maurya, A. K., R. Singh, B. Veenadhari, M. B. Cohen, S. Kumar, R. Selvakumaran, P. Pant, A. K. Singh, and U. S. Inan (2012), Morphological features of tweeks and nighttime $D$ region ionosphere at tweek reflection height from the observations in the low-latitude Indian sector, J. Geophys. Res., 117, A05301, doi:10.1029/2011JA016976.

Nagano, I., and T. Okada (2000), Electron density profiles in the ionospheric D-region estimated from MF radio wave absorption, Adv. Space Res., 25, 33-42, doi:10.1016/S0273-1177(99)00894-7.

Ohya, H., M. Nishino, Y. Murayama, and K. Igarashi (2003), Equivalent electron density at reflection heights of tweek atmospherics in the lowmiddle latitude D-region ionosphere, Earth Planets Space, 55, 627-635.

Ohya, H., K. Shiokawa, and Y. Miyoshi (2008), Development of an automatic procedure to estimate the reflection height of tweek atmospherics, Earth Planets Space, 60, 837-843.

Ohya, H., K. Shiokawa, and Y. Miyoshi (2011), Long-term variations in tweek reflection height in the D and lower $E$ regions of the ionosphere, J. Geophys. Res., 116, A10322, doi:10.1029/2011JA016800.

Outsu, J. (1960), Numerical study of tweeks based on wave-guide mode theory, J. Proc. Res. Inst. Atmos., 7, 58-71.

Pasko, V. P., U. S. Inan, Y. N. Taranenko, and T. F. Bell (1995), Heating, ionization and upward discharges in the mesosphere, due to intense quasielectrostatic thundercloud fields, Geophys. Res. Lett., 22, 365-368, doi:10.1029/95GL00008

Prasad, R. (1981), Effects of land and sea parameters on the dispersion of tweek atmospherics, J. Atmos. Terr. Phys., 43, 1271-1277, doi:10.1016/ 0021-9169(81)90151-3.

Rakov, A., and M. A. Uman (2006), Lightning: Physics and Effects, Cambridge Univ. Press, New York.

Ramachandran, V., J. N. Prakash, A. Deo, and S. Kumar (2007), Lightning stroke distance estimation from single station observation and validation with WWLLN data, Ann. Geophys., 25, 1509-1517, doi:10.5194/ angeo-25-1509-2007.

Reid, G. C. (1977), The production of water-cluster positive ions in the quiet daytime D region, Planet. Space Sci., 25, 275-290, doi:10.1016/ 0032-0633(77)90138-6.

Reznikov, A. E., A. I. Sukhorukov, D. E. Edemskii, V. V. Kopeikin, P. A. Morozov, B. S. Raybov, A. Y. Shchekotov, and V. V. Solovev (1993) Investigations of the lower ionosphere over Antarctica via ELF-VLF radio waves, Antarct. Sci., 5, 107-113.

Rodger, C. J. (2003), Subionospheric VLF perturbations associated with lightning discharges, J. Atmos. Sol. Terr. Phys., 65, 591-606, doi:10.1016/S1364-6826(02)00325-5.

Rodger, C. J., M. Cho, M. A. Clilverd, and M. J. Rycroft (2001), Lower ionospheric modification by lightning-EMP: Simulation of the nighttime ionosphere over the United States, Geophys. Res. Lett., 28, 199-202, doi:10.1029/2000GL011951.

Rodger, C. J., S. W. Werner, J. B. Brundell, N. R. Thomson, E. H. Lay, R. H. Holzworth, and R. L. Dowden (2006), Detection efficiency of the VLF World-Wide Lightning Location Network (WWLLN): Initial case study, Ann. Geophys., 24, 3197-3214, doi:10.5194/angeo-24-3197-2006.

Scherrer, D., M. B. Cohen, T. Hoeksema, U. S. Inan, R. Mitchell, and P. Scherrer (2008), Distributing space weather monitoring instruments and educational materials worldwide for IHY 2007: The AWESOME and SID project, Adv. Space Res., 42, 1777-1785, doi:10.1016/j.asr. 2007.12.013.

Shvets, A. V., and M. Hayakawa (1998), Polarization effects for tweek propagation, J. Atmos. Sol. Terr. Phys., 60, 461-469, doi:10.1016/ S1364-6826(97)00131-4

Singh, R., B. Veenadhari, M. B. Cohen, P. Pant, A. K. Singh, A. K Maurya, P. Vohat, and U. S. Inan (2010), Initial results from AWESOME VLF receivers: Setup in low latitude Indian region under IHY2007/ UNBSSI program, Curr. Sci., 98(3), 398-405.

Singh, R., B. Veenadhari, A. Maurya, M. Cohen, S. Kumar, R. Selvakumaran, P. Pant, A. Singh, and U. Inan (2011), D-region ionosphere response to the total solar eclipse of 22 July 2009 deduced from ELF-VLF tweek observations in the Indian sector, J. Geophys. Res., 116, A10301, doi:10.1029/2011JA016641. 
Subbaraya, B. H., S. Prakash, and S. P. Gupta (1983), Electron densities in equatorial lower ionosphere from the Langmuir probe experiments conducted at Thumba during the years 1966-1978, Sci. Rep. ISRO-PRLSR-15-83, Indian Space Res. Org., Bangalore, India.

Sugiyama, T. (1988), Response of electrons to a gravity wave in the upper mesosphere, J. Geophys. Res., 93(D9), 11,083-11,091, doi:10.1029/ JD093iD09p11083.

Sukhorukov, A. I., and P. Stubbe (1997), On ELF pulses from remote lightning triggering sprite, Geophys. Res. Lett., 24, 1639-1642, doi:10.1029/ 97GL01602.

Thomson, N. R. (1993), Experimental daytime VLF ionospheric parameters, J. Atmos. Sol. Terr. Phys., 55, 173-184, doi:10.1016/0021-9169 (93) $90122-\mathrm{F}$.

Thomson, N. R., and W. M. McRae (2009), Nighttime ionospheric $D$ region: Equatorial and nonequatorial, J. Geophys. Res., 114, A08305, doi:10.1029/2008JA014001.

Thomson, N. R., M. A. Clilverd, and W. M. McRae (2007), Nighttime ionospheric $D$ region parameters from VLF amplitude and phase, J. Geophys. Res., 112, A07304, doi:10.1029/2007JA012271.
Uman, M. A. (1987), The Lightning Discharge, Int. Geophys. Ser., vol. 39 Academic, San Diego, Calif.

Voss, H. D., M. Walt, W. L. Imhof, J. Mobilia, and U. S. Inan (1998), Satellite observations of lightning-induced electron precipitation, J. Geophys. Res., 103, 11,725-11,744, doi:10.1029/97JA02878.

Wait, J. R., and K. P. Spies (1964), Characteristics of the Earth-ionosphere waveguide for VLF radio waves, Tech. Note 300, Natl. Bur. of Stand., Boulder, Colo.

Weidman, C. D., and E. P. Krider (1986), The amplitude spectra of lightning radiation fields in the interval from 1 to $20 \mathrm{MHz}$, Radio Sci., 21 , 964-970, doi:10.1029/RS021i006p00964.

Yamashita, M. (1978), Propagation of tweek atmospherics, J. Atmos. Terr. Phys., 40, 151-156, doi:10.1016/0021-9169(78)90019-3.

Yano, S., T. Ogawa, and H. Hagino (1989a), Waveform analysis of tweek atmospheric, Res. Lett. Atmos. Electr., 9, 31-42.

Yano, S., T. Ogawa, and H. Hagino (1989b), Fading phenomena of whistler waves, Res. Lett. Atmos. Electr., 9, 97-107.

Yedemsky, D. Y., B. S. Ryabov, A. Y. Shchokotov, and V. S. Yaratsky (1992), Experimental investigations of tweek field structure, Adv. Space Res., 12, 251-254, doi:10.1016/0273-1177(92)90066-7. 